\title{
SEMPREVIVA, DE ANTÔNIO CALLADO, E A MULTIPLICAÇÃO DE SENTIDOS*
}

Marta Morais da Costa ${ }^{* *}$

Diziam que Callado era o único britânico nascido em Niterói.

Britânico nas suas atitudes, nos seus gostos

e na elegância de seu texto.

Mas acho que ele era mesmo de uma raça especial de brasileiros,

hoje tristemente em extinçāo.

É outro que vai faltar na barricada.

Luís Fernando Verissimo, 3l de janeiro de 1997.

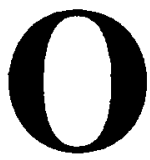

centro geográfico do Brasil é um gigantesco formigueiro. Nele, a expedição de Fontoura sepulta as esperanças de um país com saúde e sem saúvas. Quarup exorciza esta incomensurável frustração com um aceno à luta armada, assumida por Nando ao final da epopéia.

* Gostaria que este trabalho representasse minha homenagem à pessoa de Antônio Callado, um intelectual que engrandeceu o país e me ensinou a diferença entre o que é e o que poderia ser o Brasil.

** Universidade Federal do Paraná. 
A leitura da obra ficcional de Antônio Callado desfaz a imagem de um eixo da realidade nacional existente numa geografia demarcada e a refaz, prismatizada, em espaços do imaginário brasileiro. Não há menos Brasil em Madona de cedro, em Memórias de Aldeham House, em Concerto carioca do que em Expedição Montaigne, Reflexos do baile ou Sempreviva. Seja como contista, jornalista, romancista ou biógrafo, Antônio Callado continua a falar, sempre, do Brasil, um país dolorido, uma cicatriz de sonhos desfeitos, uma esperança recoberta pela ruina e pela degradação.

Em sua derradeira entrevista à Folha de S. Paulo ${ }^{1}$, publicada dois dias antes de sua morte, o escritor, amargo e doente, dizia: "Lutei muito, é verdade... E não deu em nada. Hoje, eu realmente não acredito em coisa nenhuma que possa acontecer no Brasil ou aos homens, de um modo geral." Essa descrença, contudo, não é postulada em sua obra: ao contrário, a crença no país é sempreviva.

No painel que desenhou com cuidados de muralista e consciência de homem político, Antônio Callado encontra o centro histórico do país num de seus períodos mais cruéis : o da ditadura militar pós-64. O embate ideológico e bélico criou terreno propício ao amordaçamento da liberdade e ao exercício dos instintos mais baixos do ser humano. Dessa lama social emergem figuras heróicas mas destroçáveis e lutas meritórias fadadas ao desastre, que vão se constituir nas efabulaçōes de seus romances mais importantes.

Sempreviva, lançado em 1980, quando a distensão política já se fazia sentir, trouxe enquanto literatura uma forma sublimada de julgamento dos anos da impiedosa guerra, então silenciada, ocorrida ao longo do período da ditadura. Nele se fundiram duas perspectivas diferentes de narração: a realista e a mítica. A narrativa se apresenta com a aparência de investigação e busca somada a uma história de vingança. É a perspectiva do discurso realista que retrata situações que poderiam ter sido reais e que guardam semelhanças com fatos da história político-social brasileira. Há uma segunda narrativa, paralela, que trata as situações romanescas simbolicamente, criando um nível de analogias - e consequientemente de interpretação - de sentidos acumulados. $O$ objetivo deste estudo é apresentar como se integram essas duas perspectivas em alguns fragmentos do texto.

Recordando rapidamente a fábula de Sempreviva podemos assim resumila: Vasco Soares, o protagonista Quinho, sob o disfarce de membro de uma sociedade internacional de proteção à vida selvagem, está encarregado de realizar uma reportagem sobre o onceiro Antero Varjão, nova identidade do

1 SUZUKI JR, Matinas; STYCER, Maurício. Antônio Callado chega aos 80 e revê obra. Folha de S. Paulo, 26 jan. 1997. 
ex-policial e torturador Claudemiro Marques, e sobre sua fazenda, La Pantanera, também denominada Onça Sem Roupa, situada na cidade de Corumbá, no Mato Grosso.

O motivo verdadeiro, contudo, é descobrir se e onde poderiam estar enterradas Corina e Verônica, duas guerrilheiras, assassinadas provavelmente pelo ex-policial. Com o auxílio de Jupira Iriarte, com quem se envolve afetivamente, em especial porque ela se assemelha com Lucinda, sua amada, morta pelas forças da repressão, Quinho é responsável pela morte de Antero ao usar como estratagema embebê-lo em sangue de onça, o que açula os cães da fazenda, que o estraçalham.

Após cumprir sua missão descobrindo os corpos na fazenda e vingando as moças com a morte de Antero/Claudemiro, Quinho prepara-se para deixar Corumbá com Jupira mas é avisado por uma carta, vinda de Londres, da real identidade de Juvenal Palhano, amigo de Jupira. Trata-se na verdade do médico legista Ari Knut, co-responsável com Claudemiro pela morte de Lucinda nos porões da tortura. Ao procurá-lo para vingar-se, encontra-o morto pela picada da cobra Joselina, animal de estimação de Herinha, filha de Jupira, que tentava ela também vingar a morte de seu macaco Jurupixuna, torturado pelo mesmo Antero/Claudemiro.

Quinho, logo em seguida, é assassinado por um dos capangas de Antero, que o vigiava a mando de Ari Knut.

Na construção desse esboço descarnado do romance Sempreviva já sobressaem algumas estratégias narrativas próprias da obra de Antônio Callado: a história recente da ditadura brasileira, os comportamentos amorosos, a recusa do herói idealizado, entre outras. Existe, porém, um recurso ao imaginário coletivo e às narrativas simbólicas que introduz um tratamento estético incomum aos demais romances do autor. Trata-se da superposição de camadas de sentidos, que criam uma espécie de estrato subterrâneo que vem seguidamente à luz, que se faz visível no tecido da enunciação e que constituirá um procedimento de construção basilar na composição da narrativa. O leitor se verá, então, pressionado ao resgate de múltiplos sentidos, de fatos e de faces como se fosse Quinho, ele também, a desenterrar os corpos de Corina e Verônica.

Sempreviva inicia com o protagonista se preparando para entrar clandestinamente no Brasil, via Corumbá, após anos de exílio. Mal sabe ele que estará descobrindo o centro geográfico de sua vida, seu axis mundi. Acompanhao a memória de Lucinda, sequiestrada de sua companhia dentro de um cinema do Rio de Janeiro. Este é o primeiro motivo condutor da trama: o filme interrompido que permanece como se fosse um copo suspenso no ar. A procura por Corina e Verônica repete em Quinho a procura de Lucinda, igualmente desaparecida. Enquanto não a reencontrar, o copo permanecerá suspenso. 
A história vai sendo contada no compasso temporal das ações de Quinho, entremeadas com as lembranças do passado e com as reflexões interiores de todas as personagens. Trata-se de um narrador múltiplo, pois permite a alternância de vários narradores-personagens que assumem a posição de narrador em fragmentos em primeira pessoa com caracterização pela fala, sem necessidade de uma outra voz que o identifique. Desta forma, quando Antero Varjão, que se expressa numa variante escatológica da língua portuguesa, ocupa a função de narrador, o leitor facilmente o identifica, sem necessitar de apresentação. Da mesma forma, Juvenal Palhano e sua linguagem metafórico-poética.

O tempo da narração acompanha o ritmo das personagens no tempo presente. $O$ passado somente se tornará conhecido homeopaticamente, à medida que a memória de cada personagem for atuando. É como se, sob o leito da história presente, corresse um rio subterrâneo, de águas profundas e em redemoinho que, com freqüência, irrompe. Aí então os tempos se misturam, as personagens se desdobram em faces e nomes, os lugares se aparentam e o passado não se descola do presente.

Para orientar a operação de leitura, o narrador retorna sistematicamente a motivos e analogias, acrescentando a cada repetição um novo prisma. Desta maneira, a narrativa vê surgir sua unidade pela superposição de camadas de sentidos.

Quinho é personagem obsessiva, revelada em seus cacoetes (o olhar dirigido continuamente para a cicatriz na mão esquerda, o gesto de afrouxar o nó da gravata imaginária), na persistência com que a memória recompõe as mesmas cenas, na fixidez da intenção de vingança. Cabe a ele, na solidão da busca, proceder à descoberta e posterior desenterramento dos cadáveres de Corina e Verônica. Este episódio divide o romance em duas partes e desvenda o procedimento basilar de sua construção. Sempreviva trata da revelação do que subjaz, do que está oculto por uma camada de máscaras, de enganos, de tempo decorrido, de memória sufocada. Desenterramento significa, portanto, tanto exumar como tirar do esquecimento.

A viagem de Quinho atravessando a fronteira em Corumbá é o início de um processo de reencontro com o Brasil e com o passado, e se transforma no relato de como se pode retomar o filme interrompido, completar a trajetória do copo rumo ao chão, retomar comportamentos e natureza pretéritos, entrar na "sinuosa parábola do tempo 2". A viagem, portanto, não é espacial e sim temporal e psíquica. $\mathrm{O}$ adentrar em casas significa reviver o passado. La Pantanera é

2 CALlado, Antônio. Sempreviva. Rio de Janeiro: Nova Fronteira, 1981. p. 155. A partir deste momento todas as citações desta obra serão acompanhadas da abreviatura SV, seguida do número da página em que está o trecho citado. 
dividida em aposentos mobiliados como salas de delegacia; a casa de Jupira é uma espécie de território ancestral em que homens e bichos se irmanam em comportamentos e feições; a casa de Juvenal convida a reviver a infância e o tempo da juventude ( Juvenal, por sua etimologia latina, remete a juvenil, por isso Quinho o considera um redivivo Tio Lulu). Corumbá se transforma em cixo do mundo ${ }^{3}$, local onde se processa a passagem iniciática do protagonista, do não-saber ao saber, da vida à morte.

Sem essa camada subterrânea, Sempreviva contaria, de uma perspectiva de romance de enigma somado a uma obra de denúncia, a história da descoberta de um crime (o assassinato sob tortura de duas moças) e do castigo a seus assassinos (Antero Varjão e Ari Knut). Seria um romance em que a violência, à maneira de Rubem Fonseca, comandaria todas as sequêencias narrativas e os atos das personagens. A diferença se faz no plano analógico pois, à medida em que a narrativa caminha, o leitor toma consciência de que há outros níveis de sentido sob o primeiro enunciado. Ele é convidado a ler as palavras e as frases num discurso paralelo não evidenciado, cifrado num código que só se dá a conhecer em decorrência de um entrelaçamento de sentidos anunciados nos silêncios do discurso ou na combinação das metáforas do texto.

Analisando os principais motivos associados ${ }^{4}$ sobre os quais se assenta o sentido de Sempreviva, falemos primeiramente do motivo do copo suspenso que se projeta além da interrupção causada pela tortura e morte de Lucinda, se estende pelo exílio de Quinho e acaba por significar o silenciamento e clandestinidade impostos ao país e a alguns de seus habitantes:

O me arrancarem Lucinda dos braços me pôs, digamos assim, na romaria, na peregrinação, para reatar, não no plano físico, é lógico, mas no de uma libertação que me é exigida, aquele momento que ficou, de uma forma muito literal, no espaço, feito um copo que se vai estilhaçar no chão mas lá não chega, gestos e copos e cópulas sem consumação. (SV, p.72-73)

O próprio texto esclarece que o escuro do cinema é como se fosse uma "missa negra" (Sv, p.235), marcando o caráter ritualístico e simbólico da metáfora da separação. Quinho é, portanto, um peregrino que busca dar con-

3 ELIADE, Mircea. Mito e realidade. São Paulo: Perspectiva, 1972.

4 TOMACHEVSKI, B. Temática. In: EIKHEMBAUM, B. e outros. Teoria da literatura: formalistas russos. Porto Alegre: Globo, 1971. p. 169-204. 
tinuidade ao movimento do copo, reconstituir o hiato e vingar a morte da mulher amada, e, de maneira sublimada, reencontrar Lucinda, cujo nome em sua etimologia remete a luz e a iluminada. Do escuro para a claridade, estabelece-se neste momento a relação entre o movimento do copo e a metáfora do olhar que implica outra correspondência, a da passagem do não-saber ao saber ${ }^{5}$. Sua peregrinação se assemelha à indispensável purgação de Delfino em $A$ madona de cedro ${ }^{6}$, estágio necessário para que se possa consumar a indispensável ordem do mundo.

Uma das maneiras com que a linguagem literária de Sempreviva manifesta a ligação entre o real e o mítico é a multiplicação de formas da metáfora dos olhos, com todo seu séquito de imagens visuais ou objetos que os prolongam, como o binóculo, o pincenê e a máquina fotográfica. Este motivo, por sua repetição, se converte em símbolo: "O símbolo vale por sua reiteração. É este emprego repetido que lhe permite dizer outra coisa do que aquela que ele diz e de confirmar este dito. É esta repetição também que constitui o índice e prova de uma emersão do inconsciente."

O primeiro momento de impacto é o do relato da primeira visita a $\mathrm{La}$ Pantanera, quando Quinho registra com o olho da câmera o que encontrou na fazenda de Antero Varjão:

Eu fingi que tinha esquecido a máquina grande para poder ir fotografando com a outra, de bolso, o que valesse documentar, e quase me perco, abalado, estonteado, entre as onças meio esfoladas, como se estivessem se despindo na hora da morte, onças nuas, sem roupa, como diz o povo, seminuas e semimortas, feito uma, a mais comovente, uma oncinha, que eu acho que mal tinha trocado os dentes de leite, que não mostrava nem furo de bala, só mesmo aquele pico mínimo de faca, de zagaia, no pêlo sedoso da garganta, como se a oncinha tivesse começado a se desabotoar antes de ir para a cama, antes de fechar a janela por onde ia entrar o assassino. Aí, no momento em que já estava ouvindo bem perto o tal de Dianuel rangendo e rinchando, eu, com medo de perder a oportunidade, meti a câmara na cara mesmo da oncinha e quando o olho da máquina piscou diante do

5 CHAUI, Marilena. "Janela da alma, espelho do mundo." $I n$ : NOVAES, Adauto e outros. Oolhar. 3. ed. São Paulo: Companhia das Letras, 1990, p. 31-64.

6 CALLADO, Antônio. A madona de Cedro. 3.ed. Rio de Janeiro: Nova Fronteira, 1981.

7 "Le symbole ne vaut que par sa réitération. C'est cet emploi répété qui lui permet de dire autre chose que ce qu'il dit et de confirmer ce dire. C'est cette répétition aussi qui constitue lindice et le gage d'une émergence de l'inconscient." (GALLIOT, Jean le. Psichanalyse et langages littéruires: théorie et pratique. Paris: Ed. Fernand Nathan, 1977. p. 75. Tradução minha.) 
olho dela, que eu achava e jurava que já era um olho baço, de vidro, sem mais lustro nenhum, aí saltou da pupila dela aquela chispa que talvez não fosse mais vida mesmo, vida-vida, como é que se há de saber, mas que eu garanto que era uma faísca de medo, de bicho morrendo não só aos poucos como de medo, $\mathrm{e}$ fiquei pensando, sabe, no pôster medonho, esse, do olho apavorado do bicho... (SV, p. 50)

Não se trata, como a própria Jupira diz a seguir, de fotos descompromissadas com os objetivos de Quinho de descobrir Knut e as moças torturadas. Na verdade, esses olhos amedrontados são os de Violeta e Corina, os de Jurupixuna, os das demais vítimas do onceiro. Os olhos dos torturados políticos. Denunciam a maldade em estado puro, o contato das vítimas com o profundo Mal, que é Claudemiro, nome derivado de Cláudio, que significa "coxo", não por acaso um dos codinomes do Diabo. São os olhos de Jupira ao enfrentar o lacrau, é o olhar de Knut no momento da revelação de sua identidade - olhos de lagartixa a atrair a mariposa Jupira.

Trata-se de um saber intraduzível em palavras, um brilho que a vítima registra e perpetua. São os olhos que Jupira evita ver, rejeição expressa numa transferência sinestésica muito significativa : "os olhos que ela tinha medo de ver nas mãos de Quinho talvez o tivessem assombrado tanto por serem, parecerem ou simplesmente lembrarem as circunstâncias da morte, ou do cinema, ou da mesa de mármore, ou..." (SV, p. 69-70).

O olhar de Juvenal se estende ao pincenê, objeto mágico, contaminado pelo poeta das estrelas, Olavo Bilac, seu primeiro dono. Suas lentes refletem estrelas, mas só no momento em que Juvenal, retomando a identidade de Ari Knut, trama a prisão de Quinho:

(...) tão emocionado que, num instante em que Ari Knut, num floreio quase de esgrimista, ergueu nos ares o pincenê, ele viu, como nos contos de assombros e magias, que as lentes piscavam e pulsavam de estrelas como um céu de serenata. (SV, p. 253)

É novamente o brilho do Mal associado à morte, apesar do tom encantatório do discurso do narrador.

Novo sentido, nesta mesma isotopia, pode ser documentado na associação com os olhos da serpente e de Herinha. A menina tem "o castanho-mel dos seus olhos, que interrogam os olhinhos das serpentes, mínimos, incapazes 
de retribuir a claridade dos olhos dela" (SV, p. 127). Herinha personifica a comunhão entre o ser humano e a natureza, união que lhe permite assumir seu papel de protetora (Hera etimologicamente significa "a forte, a protetora") no momento em que o equilíbrio de seu habitat se vê ameaçado. É ela quem leva a Juvenal Palhano a chapeleira contendo a serpente que o mata. Quando ela chega à casa dele é descrita como "clara mensageira, luminosos olhos um tantinho luminosos demais, fatais que seriam um dia, se já não eram" (SV, p. 278).

A luz, os olhos e a fatalidade novamente se apresentam conjugados. A descrição dessa chegada é feita pela voz de Palhano que interpreta a fatalidade num sentido erótico, pois acredita estar recebendo de presente o canário Venturino, conduzido na chapeleira. $O$ canário era objeto de prazer para Juvenal que acreditava ser seu canto superior ao de Caruso. O ex-torturador impusera como preço à vida de Jupira a entrega do canário que pertencia a sua filha e que se constituía, com a cascavel Joselina e o macaco Jurupixuna, animais amados pela menina. Entregar Verdurino era morrer um pouco. Por isso Herinha coloca a serpente na chapeleira e a entrega a Juvenal. Ela é a mensageira da morte: o leitor sabe disso, a personagem não, e por isso morre. Para o leitor, portanto, a palavra "fatalidade" na frase que descreve a chegada da menina carrega um sentido mortal, ainda mais que o motivo dos olhos precedentemente já se haviam associado ao Mal e à morte.

A serpente, por sua vez, não é apenas um motivo associado ao desenlace da ação, é um animal mítico. $O$ narrador atribui a ela dois ofícios ancestrais. $O$ primeiro é o de simbolizar o tempo e a vida, sentido aclarado pelo texto: "sem sequer olhar de novo a sala onde o relógio-de-armário parecia não mais descascar o tempo como uma laranja, numa roda, numa cobra enrolada em si mesma, perigosa e finita: ia de novo em frente, marchando adiante, avante e arriba." (SV, p. 284).

A esta imagem da serpente, pertencente à mitologia universal, Callado acrescenta um segundo mérito, que a aproxima, metaficcionalmente, do contador de histórias:

Joselina cra uma cobra costureira e sábia, que (enquanto chocalhava se estojos de agulhas, as almofadas de alfinetes de cabecinha) aguardava que Herinha deixasse cair na cesta de costura os retalhos que tinha juntado de conversa de gente grande e zás! - num segundo Joselina tinha entendido e armado o desenho que contava a história que, embora feita de remendos coloridos, diferentes entre si, era completa, como uma roupa de arlequim 
(...) os panos de Joselina iam contar a Herinha a história feita de todas as histórias. (Sv, p.147-8)

Esta sábia costureira, esta Parca em forma animal, representa o tempo e a História, que, como sabemos, são indissociáveis. A cascavel Joselina, metáfora do contador de histórias, pode ser lida numa perspectiva mítica, retomando a imagem do que subjaz, da "terra dentro da terra" (SV, p. 165), base da narrativa de Sempreviva. Como a serpente, o narrador deste romance também costura retalhos coloridos - monólogos, diálogos e narração - expressos nos mais diferentes registros da língua, em tempos que se alternam, em imagens e motivos que retornam insistentemente, para, num caleidoscópio ficcional, envolver o leitor, encantá-lo, como o olhar da serpente encanta o passarinho, porque conhece a história do mundo e dos homens.

Quando se dá a morte de Antero Varjão, devorado pelos cães por ele mesmo ensinados a estraçalhar qualquer organismo banhado em sangue de onça, o texto de Sempreviva desvenda novamente seus subterrâneos. Desta feita, mostrando sua simetria com narrativas primordiais.

A morte do onceiro é contada em formato coletivo como a se constituir $\mathrm{em}$ mais um retalho para o tapete vivo das histórias:

(...) vindas das ruas, as vozes das criadas, das comadres, dos entregadores, dos marujos e vaqueiros de água doce (...) reunidas e reforçadas pela voz atávica e sapiente, medida em redondilhas para ficar mais fácil de decorar, dos poetas repentistas, dos violeiros, esse imenso coral de cordel, ocupado em vestir de palavras e nutrir de lendas e narrativas auxiliares a fábula que acabava de nascer ali mesmo, em fazenda da região, num presépio talvez sinistro (...) (SV, p. 288)

O título do romance Sempreviva aponta, por esta razão, para duas direções interpretativas. Lucinda é eterna na lembrança de Quinho que, ao morrer, "teve tempo de ver o copo que afinal se estilhaçava no chão. E desta vez ele guardou para sempre, na sua, sem soltá-la, a mão de Lucinda, e guardou ela própria, toda ela, Lucinda perene, perpétua, imortal, sempreviva." (SV, p. 289). O romance seria, nesta linha de raciocínio, a narrativa de uma amor eterno, de um encontro amoroso retardado pela violência da repressão e que só se realiza além da morte.

Mais forte que a civilizada gravata que o sufocava mesmo sem existir, mais forte do que a cicatriz-tatuagem que o enlaçava com o tempo pretérito de 
caçador de pássaros - convertido no presente em caçador de homens - era a imagem onipresente de Lucinda. Mesmo Jupira (em tupi, "alimento") só significa alguma coisa para ele porque lembra a amada morta. Ela representa a concretude em que se enlaça, é a contraparte carnal daquela que já não é. Ao sonhar com a viagem de volta à Europa, Quinho tem, lado a lado no avião, Jupira e Lucinda, inseparáveis porque iguais. Estar com Jupira é recuperar Lucinda em memória.

Mas a própria narrativa, ao fundir o real e o mítico, se inscreve como a história nascida da necessidade do ser humano explicar o Bem e o Mal, através da linguagem narrativa, à semelhança do que fazem os mitos morais.

Na obra de Callado, a natureza tem papel preponderante em algumas narrativas, como se pode observar em Expedição Montaigne e Concerto carioca. Em Sempreviva, ela alia-se ao político para criar o tempo do castigo dos criminosos, da punição, do Juízo. A natureza, representada pela serpente Joselina e pelos cachorros, se encarrega de fazer cumprir o princípio da justiça, que corria o risco de não se concretizar por incapacidade dos homens. Esta integração entre a natureza e os homens é responsável pela leitura mítica que se pode realizar desse romance, de vez que procura estabelecer uma sociedade definida a partir de um comportamento próprio de sociedades ancestrais. Neste sentido, convém recordar que o espaço dominado por Herinha e habitado por seus bichos - com os quais conversa e trata como se fossem pessoas - ela denomina Pai, ou seja, fica implícita nesta denominação a idéia de origem, de ancestralidade.

Acompanhando no mesmo diapasão essa fusão do real e do mítico, pode-se verificar como o escritor cria homologias entre a forma expressiva e a intenção da narrativa mítica.

Assim como as personagens mudam de pele ao adotar nomes diferentes e disfarces, tentando estabelecer rupturas no fluxo da história e do tempo, assim também a linguagem abandona a construção frasal em ordem direta, revolucionando-a, rompendo nexos causais, usando a frase caudalosa, interrompida freqüentemente por anacolutos, orações intercaladas e uma virgulação extremada. Pela mesma razão as imagens se acumulam e entrançam e, muitas vezes, surgidas da percepção dos sentidos, precipitam-se na sinestesia, mostrando uma realidade embaralhada, de correspondências, sensorial, até mesmo barroca:

8 GALLIOT, op. cit. p. 84. O autor divide a mitologia em cinco conjuntos: os mitos tcogônicos ( relatam a origem e a história dos deuses), os mitos cosmogônicos (se referem à criação do mundo), os mitos etiológicos (sobre a origem dos seres e das coisas), os mitos escatológicos (evocam o futuro e o fim do mundo) c, finalmente, os mitos morais, concernentes à luta entre o Bem e o Mal. 
"Recortada por abundante pontuação, a linguagem traz ao centro de luz sequiências locucionais, frases intercaladas, abrindo-se em flor, cheia de pontas, aquecida pela comparação e o símile".

Exemplos já podem ter sido observados nas citações do romance feitas anteriormente. Acrescentemos, porém, algumas outras: "silêncio úmido das entranhas da pedra" (SV, p. 185) ; "a cristaleira, achacada, reumática, se plangia em suspiros e ai-jesuses, mal a casa se aquietava, queixando-se do peso dos vidros e porcelanas em cima das prateleiras, lamentando-se dos batoques de pau em suas articulações e juntas" (SV, p. 198); "a camisa de Quinho tinha manchas de sangue (...) que tornavam concreta, vermelha, rubra, a história contada (...) ali estava escarlate, a prova provada, e, por assim dizer, verônica da história, a camisa." (SV, p. 203); "os homens, em disciplinada exaltação, fabricando a exata ambrosia, o rigoroso manjar que arredonda os seios e os quadris daquela que tira seu sustento de nossa harmonia, de nossa ordem [a personagem está se referindo ao surgimento da lenda a respeito da morte de Varjão]." (SV, p. 214).

As sinestesias se multiplicam por todo o texto de Sempreviva, criando uma linguagem narrativa que se aproxima da poesia e que difere amplamente dos demais romances de Callado, cumprindo uma função que ModestCarone define muito bem ao tratar da poesia de Georg Trakl:

....as sinestesias do poeta têm a função de intensificar a vitalidade metafórica do discurso, uma vez que o contraste entre um tipo de impressão e aquelme que é dado por outro órgão sensorial não pode passar despercebido, movendo o leitor a uma contemplação reflexiva simultânea ao longo de duas (ou mais) avenidas de sentido. "Essa desordem rudimentar dos modos de percepção" encontra eco na quebra sistemática das ligaçōes lógicas da linguagem; e, através desse procedimento reiterado, o poeta vislumbra (e faz vislumbrar) a possibilidade de se conquistarem novas "províncias da percepção".

Sensorialismo e sensualismo compõem os dois planos da linguagem estética do romance, produzindo imagens poéticas que concretizam uma realidade psíquica, comportamental e ideológica primitiva. É como se as perso-

9 COSTA, Édison José da .Quarup: tronco e narrativa. Curitiba: Editora da UFPR., p. $98,1988$.

10 CARONE NETTO, Modesto. Metáfora e montagem: um estudo sobre a poesia de Seorg Trakl. Sāo Paulo: Perspectiva, p. 87. 1974. Grifo do autor. 
nagens estivessem à mercê de seus instintos de amor, ódio, agressividade, morte e preservação, independentes da civilização. Corumbá se torna uma espaço "sem lei, sem dono, sem dó" (SV, p. 256), como o cachorro Molambo, executor da justiça no corpo de Claudemiro Marques.

Sempreviva é uma narrativa que procura ir ao encontro do mito e Antônio Callado buscou concretizar na linguagem essa metamorfose. Recorrendo novamente a Modesto Carone, podemos nos servir de sua pertinente análise e atribuí-la a Sempreviva :

...as plantas, os animais, a vida inorgânica, as estações, e as figuras que participam da montagem como elementos descontínuos, são entidades emancipadas pela fragmentação, e nas combinações metafóricas traklianas elas são tratadas exatamente como nós as experimentamos originariamente, ou seja, desamarradas dos contextos em que se haviam imobilizado e com isso remetidas ao seu flutuante enigma germinal. Isso significa que, recuperadas ao uso e ao desgaste, elas podem, agora, acionar no corpo verbal do poema a força vital mágica que em latência possuem dentro de nós, da nossa subjetividade profundamente familiarizada com elas, pois são as primeiras ofertas da criação e as primeiras lembranças da humanidade. ${ }^{11}$

A aproximação com o mito não retira do romance

O comprometimento das personagens com o ideal de emancipação nacional e popular (...) A tarefa vingadora que se atribui ao protagonista está voltada para a punição daqueles que destruíram, em 1964, o mundo que a partir da libertação e da afirmação do homem era gerado. Castigando os policiais responsáveis pela morte de Lucinda, Quinho quer restabelecer o tempo que então se desenvolvia - tempo inicial, de invenção e nascimento. $^{12}$

A conjunção dessas duas espécies narrativas acaba por construir um texto que se expande a cada gesto de leitura exercido, sem deixar de vigorar como um

11 CARONE NETO, op. cit., p. 96.

12 COSTA, op. cit., p. 130. 
relato político sobre o período de violência e impunidade que dominou o Brasil nos anos ditatoriais.

\section{RESUMO}

Análise dos componentes narrativos de Sempreviva, de Antônio Callado sob a perspectiva mítico-poética. Procura-se demonstrar como os sentidos se multiplicam com a análise de alguns motivos e símbolos presentes no romance. literária.

Palavra-chave: Antônio Callado; Sempreviva, de Antônio Callado; análise

\section{RESUME}

Ce texte est une analyse des éléments narratifs de Sempreviva, de Antônio Callado dans une perspective mito-poétique. On y essaye de démontrer comme le sens $s$ 'amplifie à partir de l'analyse de quelques motifs et quelques symboles qui composent le roman.

\section{REFERÊNCIAS BIBLIOGRÁFICAS}

CALLADO, Antônio. Madona de cedro. 2. ed. Rio de Janeiro: Nova Fronteira, 1981. Sempreviva. Rio de Janeiro: Nova Fronteira, 1981.

CARONE NETTO, Modesto. Metáfora e montagem. São Paulo: Perspectiva, 1974. COSTA, Édison José da. Quarup: tronco e narrativa. Curitiba: Editora da UFPR., 1988. EICKENBAUM, B. Teoria da literatura: formalistas russos. Porto Alegre: Globo, 1971. GALLIOT, Jean Le. Psychanalyse et langages littéraires. Paris: Fernand Nathan, 1977. NOVAES, Adauto (org.) $O$ olhar. São Paulo: Companhia das Letras, 1990.

SUZUKI Jr., Matinas; STYCER, Maurício. Antônio Callado chega aos 80 e revê obra. Folha de S. Paulo, 26 jan.1997. 